\title{
Manfaat Body Mekanik dan Hamstring Exercise terhadap Pengurangan Nyeri Pinggang Ibu Hamil Trimester III
}

\author{
Lina Puspitasari ${ }^{1}$, Ernawati ${ }^{2}$ \\ Email: Lina_Puspitasari@yahoo.co.id \\ D-III Kebidanan Akademi Kebidanan Graha Mandiri Cilacap
}

\begin{abstract}
Abstrak
Latar Belakang. Nyeri pinggang adalah nyeri pada daerah punggung bawah yang terjadi pada $50 \%$ ibu hamil dan dapat diatasi dengan latihan Body Mekanik yaitu suatu usaha memfasilitasi gerak tubuh tanpa terjadi ketegangan otot sehingga mengurangi cedera musculoskeletal.Tindakan hamstring exercise juga dapat mendukung pengurangan nyeri pinggang, hal ini disebabkan ole proses latihan berupa pengulurang yang mengakibatkan pada fleksibilas otot dan terjadinya peningkatan metabolisme tubuh. Tujuan penelitian ini adalah untuk mengetahui manfaat body mekanik dan hamstring exercise terhadap pengurangan nyeri pinggang ibu hamil trimester III. Metode Penelitian. Penelitian ini menggunakan pendekatan jenis analisis uji komparatif. Subyek dalam penelitian ini sebanyak 36 ibu hamil trimester III yang mengalami keluhan nyeri pinggang. Penelitian ini dilakukan di PMB Bidan Utami, Amd.Keb. Penelitian dilakukan pada bulan November 2018-Maret 2019. Penelitian ini menggunakan uji Wilcoxon Signed Rank dalam program software SPSS 20. Hasil penelitian ini menggunakan rumus Wilcoxon Signed Rank. Berdasarkan perhitungan hasil analisis dengan menggunakan komputerisasi didapatkan hasil nilai $Z$ sebesar - 5.255 dan nilai $p$ value (Asymp Sign 2 tailed) sebesar 0,000 dimana nilai tersebut dibawah batas kritis penelitian atau titik signifikansi $0,05(5 \%)$ dan nilai $Z$ table sebesar 1.68830. Simpulan dari penelitian ini adalah terdapat manfaat body mekanik dan hamstring exercise terhadap pengurangan nyeri pinggang ibu hamil trimester III.
\end{abstract}

Kata kunci: Humstring Exercise, Body Mekanik, Nyeri Pinggang, Ibu Hamil.

\begin{abstract}
Background. Low back pain is the pain in the lower back region that occurs in $50 \%$ of pregnant women and it can be overcome with training. Mechanical Body is an effort to facilitate muscle movement without causing muscle tension so as to reduce musculoskeletal injury. Hamstring exercise action can also support the reduction of low back pain, this is caused by the exercise process in the form of a reduction that results in muscle flexion resulting in reduced muscular injury and an increase in body metabolism. The purpose of this study was to determine the benefits of body mechanics and hamstring exercise on the reduction of low back pain in third trimester pregnant women. Research methods. This study uses a comparative test analysis type approach. Subjects in this study were 36 third trimester pregnant women who experienced complaints of low back pain. This research was conducted at PMB Midwife Utami, Amd.Keb. The study was conducted in November 2018-March 2019. This study used the Wilcoxon Signed Rank test in the SPSS 20 software program. The results of this study used the Wilcoxon Signed Rank formula. Based on the calculation results using a computerized analysis of the results obtained $\mathrm{Z}$ value of 5.255 and $p$ value (Asymp Sign 2 tailed) of 0,000 where the value is below the critical limit of research or a point of significance of $0.05(5 \%)$ and $\mathrm{Z}$ table value of 1.68830 . The conclusion of this study is that there are benefits of mechanical body and hamstring exercise on the reduction of low back pain in third trimester pregnant women.
\end{abstract}

Keywords: Hamstring Exercise, Mechanical Body, Low Back Pain, Pregnant Women.

\section{Pendahuluan}

Masa kehamilan merupakan suatu keadaan fisiologis yang menyebabkan hampir seluruh tubuh wanita mengalami perubahan, terutama pada alat- alat kandungan, dan juga organ lain yang menunjang perkembangan dan pertumbuhan 
janin. ${ }^{[1]}$ Perubahan-perubahan yang terjadi yaitu perubahan pada uterus, serviks, ovarium, vagina, kulit, payudara, metabolik, kardiovaskuler, traktus digestivus, traktus urinarius, sistem endokrin, dan sistem muskuluskeletal. ${ }^{[2]}$

Perubahan fisiologis juga dapat menimbulkan ketidaknyamanan yang dirasakan oleh ibu, antaralain; rasa mual dan muntah pada awal kehamilan,gusi berdarah hingga sakit gigi, peningkatan pigmen yang mengakibatkan terjadinya chloasma atau topeng kehamilan di wajah, dan perubahan postur tubuh secara bertahap seiring bertambahnya usia kehamilan dapat mengakibatkan nyeri pinggang.

Nyeri pinggang, dalam masa kehamilan merupakan salah satu problem yang banyak dikeluhkan oleh para calon ibu. Berdasarkan penelitian mayer dan rekan sekitar $50 \%$ ibu hamil sering mengeluhkan sakit pinggang saat menjalani proses kehamilan. ${ }^{[3][4]}$ Sementara menurut Kusmaryadi (2011), sekitar 50- 70\% dari wanita hamil pada umumnya mengeluh nyeri pinggang yang bisa dirasakan disemua tingkat usia kehamilan. Namun, nyeri ini paling banyak dirasakan saat kehamilan tua.

Pengertian nyeris sendiri adalah campuran reaksi fisik, emosi, dan perilaku. Stimulus penghasil nyeri mengirimkan impuls melalui serabut saraf perifer. Serabut nyeri memasuki medulla spinalis dan menjalani salah satu dari beberapa rute saraf dan akhirnya sampai di dalam massa berwarna abu-abu di medulla spinalis. Terdapat pesan nyeri dapat berinteraksi dengan saraf inhibitor, mencegah stimulus nyeri sehingga tidak mencapai otak atau ditransmisi tanpa hambatan ke korteks serebral, maka otak menginterpretasi kualitas nyeri dan memproses informasi tentang pengalaman dan pengetahuan yang lalu serta asosiasi kebudayaan dalam upaya mempresepsikan nyeri.
Nyeri pinggang pada kehamilan sering disebabkan karena relaksasi sendi pelvis akibat perubahan hormonal. Sejalan dengan bertambahnya berat badan secara bertahap selama kehamilan dan terdapat pengaruh hormonal pada struktur ligament kedua faktor ini merubah postur tubuh ibu hamil. Hal ini menyebabkan kecenderungan bagi otot untuk memendek, jika otot abdomen memendek dapat menyebabkan ketidak seimbangan otot di sekitar pelvis, dan tegangan tambahan dapat dirasakan diatas ligament tersebut. Akibatnya nyeri pinggang yang biasa berasal dari sakroiliaka atau lumbal, dan dapat menjadi gangguan pinggang jangka panjang jika keseimbangan otot dan stabilitas pelvis tidak dipulihkan setelah melahirkan.

Untuk mengurangi dan mencegah keluhan nyeri pinggang dan membentuk aktivitas sehari-hari yang aman selama kehamilan maka ibu hamil perlu mekanika tubuh (body mekanik) yang benar. Mekanika tubuh (body mekanik) pada ibu hamil yaitu posisi tubuh yang baik untuk menyesuaikan perubahan tubuh pada ibu hamil terutama tulang punggung yang lordosis. Mekanika tubuh (body mekanik) pada ibu hamil meliputi cara berdiri yang benar, posisi tidur, posisi mengakat beban, dan posisi jongkok (Pusdiknakes: 2005). Body mekanik akan memfasilitasi pergerakan tubuh yang memungkinkan mobilisasi fisik tanpa terjadi ketegangan otot dan penggunaan kekuatan otot yang berlebihan. Oleh karena itu mekanika tubuh yang tepat mengurangi risiko cidera musculoskeletal termasuk daerah vertebra yang akan menyebabkan nyeri punggung atau nyeri tulang belakang.

Berdasarkan penelitian yang dilakukan Ummah (2012) dengan metode observasional analitik tentang “ Nyeri Pinggang Pada Ibu Hamil 
Ditinjau Dari Body Mekanik dan Paritas di Desa Ketanen Kecamatan Paceng Kabupaten Gresik" hasil penelitian ini menunjukan ada hubungan dan secara statistik signifikan antara body mekanik dengan nyeri punggung namun saran dari peneliti untuk penelitian selanjutnya yaitu pendudukan kesehatan tentang mekanika tubuh yang benar lebih berpengaruh terhadap nyeri pinggang sebab berkaitan dengan pola aktivitas sehari-hari. Mekanika tubuh yang tepat akan memempertahankan postur tubuh dan mengurangi resiko cidera musculoskeletal ketika ibu hamil melakukan aktivitas selama kehamilan.

Selain body mekanik yang sudah dipaparkan pada paragraf sebelumnya, humstring exercise juga dapat bermanfaat untuk mengurangi permasalahan tersebut. Inti dari gerakan humstring excercise adalah peregangan, dimana peregangan berfungsi untuk meningkatkan mobilisasi sendi, panjang otot dan fleksibilitas, serta untuk merileksasikan otot pada umumnya. $\mathrm{Kaku}$ otot diakibatkan oleh kurangnya efisiennya metabolisme sehingga mengakibatkan peningkatan tekanan intramuskuler dan penurunan sirkulasi cairan. Oleh karena itu peregangan digunakan untuk meningkatkan metabolisme (Ylien, 2007).

Frekuensi pemakaian otot hamstring sehari-hari yang berlebihan dapat mengakibatkan otot mengalami kelelahan berupa kontraktur sebagai reaksi pemendekan jaringan lunak. Kontraktur yang terjadi pada otot hamstring akan menimbulkan nyeri pada daerah posterior paha, keterbatasan gerak sendi hip dan lumbal yang berakibat pada gangguan postur serta pola jalan. Untuk mengatasi masalah tersebut, dapat dilakukan penguluran (Irfan \& Natalia, 2008).
Berdasarkan data diatas, penulis tertarik melakukan penelitian tentang "manfaat body mekanik dan hamstring exercise terhadap pengurangan nyeri pinggang ibu hamil trimester III" dengan harapan bisa memberikan asuhan kebidanan yang berkualitas.

\section{Metode Penelitian}

Desain penelitian ini adalah merupakan penelitian analitik observasional dengan desain cross sectional. Penelitian cross sectional merupakan penelitian atau pengkajian yang dilakukan peneliti sebanyak satu kali pada saat pemeriksaan. Jadi tidak diobservasi secara berkala atau terus-menerus. Serta peneliti tidak melakukan tindak lanjut terhadap hasil penelitian yang didapatkan (Sastroasmoro dan Sofyan, 2006).

Metode penelitian yang digunakan adalah penelitian eksperimental. Penelitian tentang manfaat penguatan otot abdomen dan pemijatan lumbal terhadap percepatan proses persalinan kala I dilaksanakan di PMB (Praktik Mandiri Bidan) Ny. U Kelurahan Gumilir Kecamatan Cilacap Utara Kabupaten Cilacap. Penelitian ini dilaksanakan pada bulan November 2018.

Taknik Pengumpulan data dalam penelitian ini dilihat dari segi jenis data adalah data primer dan data sekunder. Data primer dalam penelitian ini di dapat dari pengisian lembar observasi berdasarkan hasil obeservasi pembukaan servik, sedangkan data sekunder diperoleh dari pihak lain, tidak langsung diperoleh peneliti dari subyek penelitian.

Langkah-langkah tindakan hamstring exercise antara lain: 


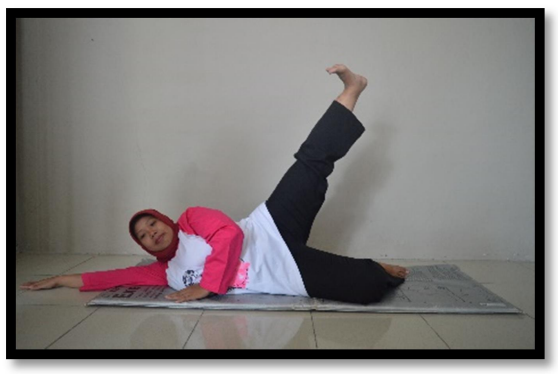

1. Posisikan ibu hamil terlentang, kemudian ajari ibu hamil rileksasi (dengan cara mengatur tarikan nafas dan mengulurkan tangan ke atas)

2. Merubah posisi ibu hamil miring ke kanan dengan posisi seperti gambar 1.

3. Mengajari ibu untuk menggerakan kaki kiri ke atas bersamaan dengan gerakan kepala ke arah atas.

4. Melakukan gerakan selama 3 kali.

5. Kemudian anjurkan ibu untuk mengubah posisi menjadi miring kiri, dan menggerakan kaki kanan ke arah atas dan lakukan 3 kali.

Langkah terakhir dari suatu penelitian adalah melakukan analisis data. Analisa data dilakukan secara bertahap dan dilakukan melalui proses komputerisasi.

a. Analisis univariat

Analisis univariat bertujuan untuk menghitung atau mencari hasil distribusi frekuensi dan prosentasi disetiap variable penelitian (Notoatmodjo 2010). Dalam penelitian ini, analisis univariat digunakan untuk mengetahui distribusi frekuensi karakteristik responden ibu bersalin dengan menggunakan rumus sebagai berikut:

$$
P=\frac{f}{N} \times 100 \%
$$

Keterangan :

$\mathrm{P}$ : Prosentase

$f$ : Frekuensi responden

$\mathrm{N}$ : Jumlah seluruh responden

100 : Bilangan Tetap b. Analisis bivariat

Teknik analisa data pada uji hipotesis yang digunakan menganalisa rumusan masalah dan hipotesis dalam penelitian ini adalah dengan menggunakan uji wilcoxon. Uji Wilcoxon Signed Rank ini merupakan suatu uji untuk membandingkan pengamatan sebelum dan sesudah perlakuan. Uji ini merupakan uji komparatif antara dua pengamatan. Skala yang digunakan dalam teknik ini adalah skala ordinal. Jenis data yang digunakan dalam uji ini adalah data kuantitatif (Sugiyono,2010).

\section{Hasil dan Pembahasan}

Analisis Univariat

Berdasarkan hasil penelitian yang dilakukan diperoleh gambaran setiap variabel yang diteliti dan ditulis dalam tebel ditribusi frekuensi sebagai berikut:

Tabel 1. Data Responden Berdasarkan Kelompok Paritas

\begin{tabular}{ccc}
\hline Paritas & $\begin{array}{c}\text { Jumlah } \\
(\mathbf{F})\end{array}$ & $\begin{array}{c}\text { Presentase } \\
(\mathbf{\%})\end{array}$ \\
\hline Primigravida & 9 & 25 \\
\hline Multigravida & 27 & 75 \\
\hline $\begin{array}{c}\text { Grande } \\
\text { Multipara }\end{array}$ & 0 & 0 \\
\hline Jumlah & 36 & 100 \\
\hline
\end{tabular}

Sumber: olahan sendiri, 2019

Berdasarkan Tabel 1
menunjukan bahwa pada
kelompok primigravida sejumlah
9 ibu $(25 \%)$, multigravida
sejumlah $27 \mathrm{ibu}(75 \%)$, grande
multipara sejumlah $0 \mathrm{ibu}(0 \%)$.
Jumlah keseluruhan ibu hamil
sebanyak 36 ibu. Jumlah
prosentase paling banyak dari data


responden berdasarkan kelompok paritas yaitu pada kelompok ibu multigravida.

Dari tabel tersebut menunjukan bahwa jumlah ibu hamil pada multigravida memiliki intensitas nyeri lebih tinggi dibanding primigravida maupun grande multipara ini sependapat dengan Setyohadi (2006) bahwa ibu hamil memiliki jumlah paritas lebih dari 2 kali telah mengalami trauma pada jalan lahir, sehingga memiliki tingkat nyeri lebih tinggi khususnya daerah sekitar punggung.

Klasifikasi nyeri berdasarkan Pekerjaan Tabel 2. Data Responden Berdasarkan Pekerjaan.

\begin{tabular}{ccc}
\hline Pekerjaan & $\begin{array}{c}\text { Jumlah } \\
(\mathbf{F})\end{array}$ & $\begin{array}{c}\text { Presentase } \\
(\mathbf{\%})\end{array}$ \\
\hline PNS & 3 & 8 \\
\hline $\begin{array}{c}\text { Ibu rumah } \\
\text { tangga }\end{array}$ & 26 & 72 \\
\hline Petani & 7 & 20 \\
\hline Jumlah & 36 & 100 \\
\hline
\end{tabular}

Sumber: olahan sendiri berdasarkan data primer

Berdasarkan Tabel 2. menunjukan bahwa sampel terdiri dari tiga kelompok yaitu kelompok ibu dengan pekerjaan PNS sebanyak 3 ibu (8\%), ibu dengan pekerjaan Ibu Rumah Tangga sebanyak $26 \mathrm{ibu}(72 \%)$, ibu dengan pekerjaan petani sebanyak $7 \mathrm{ibu}$ (20\%). Jumlah keseluruhan ibu hamil sebanyak $36 \mathrm{ibu}$, dapat disimpulkan bahwa sebagian besar subyek penelitian ini tidak bekerja atau sebagai ibu rumah tangga, sedangkan Pekerjaan rumah tangga memiliki pengaruh terhadap peningkatan nyeri, apabila jenis pekerjaan yang dilakukan tidak difasilitasi oleh mekanika tubuh yang benar sehingga dapat menjadi ketegangan termasuk daerah vertebra yang akan menyebabkan nyeri pinggang atau nyeri tulang belakang.

\section{Analisa Data}

Dari tabel diatas mengenai latihan body mekanik untuk menurunkan nyeri pinggang pada ibu hamil trimester III, dilakukan rekapitulasi data dalam tabel berikut :

Berdasarkan data diatas, pengujian hiotesa menggunakan rumus Wilcoxon Signed Rank dengan aplikasi SPSS Versi 16.0 dengan ketentuan Ho diterima apabila $\mathrm{p} \geq 0,05$, dan Ho ditolak apabila $\mathrm{p} \leq 0,05$.

\begin{tabular}{l}
\hline N \\
\hline $\begin{array}{l}\text { Z } \\
\text { Sebelum- }\end{array}$ Asymp \\
.Sig.
\end{tabular}


hasil penelitian ini sesuai dengan tujuan, maka penentuan sampel yang ditetapkan harus sesuai dengan kriteria inklusi dan eksklusi.Sampel pada penelitian ini dilakukan pada ibu hamil di PBM Bidan Utami.

Menurut Varney (2007) keparahan nyeri pinggang biasanya meningkat seiring paritas. Selain faktor paritas, risiko nyeri pinggang pada kehamilan meningkat pada wanita yang sebelumnya mengalami nyeri pinggang dan kegemukan pada saat bertambahnya usia kehamilan. Nyeri pinggang ini terutama akan meningkat pada ibu yang sudah pernah hamil (multigravida) terlebih pada grande multigravida karena adanya kelemahan otot-otot abdomen sehingga gagal menopang uterus. Hal ini akan menyebabkan uterus mengendur dan lengkung pungung semakin memanjang dan berujung pada peningkatan nyeri pinggang. ${ }^{[11}$

Salah satu kegiatan yang mengakibatkan terjadinya nyeri pinggang pada ibu hamil yaitu banyak tugas rumah tangga seperti menyetrika atau menyiapkan makanan yang dapat dilakukan dalam posisi duduk, bukan berdiri tetapi dilakukan dengan berdiri dalam waktu yang lama, termasuk jika ibu hamil harus mengangkat objek berat maka terjadi tegangan pada otot panggul, semua gerakan berputar sambil mengangkat merupakan gerakan yang berbahaya dan tidak boleh dilakukan karena dapat mengakibatkan peningkatan nyeri pinggang (Diane, M Fraser. 2009).

Dengan dilakukannya latihan body mekanik dapat menurunkan nyeri pinggang pada ibu hamil trimester III Body mekanik pada ibu hamil yaitu dapat menyeimbangkan posisi tubuh pada ibu hamil terutama tulang punggung yang lordosis. Penggunaan mekanika tubuh yang tepat dan memfasilitasi pergerakan tubuh, yang memungkinkan mobilisasi fisik tanpa terjadi ketegangan otot dan penggunaan kekuatan otot yang berlebihan sehingga dapat mengurangi terjadinya resiko cedera pada daerah otot dipinggang. ${ }^{[6][7]}$

Sejalan dengan pendapat Varney (2007) Apabila wanita hamil tidak menggunakan body mekanik yang tepat maka cedera muskuloskeletal pada daerah vertebra atau tulang belakang akan meningkat, yang akan meningkatkan nyeri punggung. Terdapat beberapa langkah sederhana yang dapat dianjurkan oleh bidan kepada ibu untuk mengurangi nyeri pinggang, seperti mempertahankan postur yang baik, dengan memperhatikan mekanisme tubuh yang baik terutama saat mengangkat benda, melakukan latihan tranversus serta latihan menengadakan pelvis dalam posisi berdiri, duduk dan berbaring, tidak berdiri terlalu lama semua kegiatan diatas adalah mekanika tubuh yang benar. ${ }^{[8][9]}$

$$
\text { Adapun pendapat }
$$

Cunningham (2005) bahwa nyeri punggung meningkat seiring usia kehamilan merupakan kejadian yang fisiologis terjadi sehingga dapat diatasi oleh tubuh dengan sendirinya serta dapat menghilang tanpa dilakukan asuhan apapun. Berdasarkan penelitian dan hasil 
olahan data, dimana terdapat keluhan pada kehamilan Trimester III di Praktek Mandiri Bidan Utami, Amd.Keb, setelah diratarata dikatakan nyeri sedang yaitu antara 3-6. Setelah di analisis jumlah sesudah dilakukan mengalami penurunan tingkat nyeri pinggang.

\section{Kesimpulan}

Berdasarkan hasil analisa data dan uji hipotesis diperoleh nilai $\mathrm{Z}$ sebesar -5.255 (nilai mutlak yaitu tidak terpengaruh nilai positif dan nilai negatif) dan nilai $p$ value (Asymp. Sign 2 tailed) sebesar 0,000 dimana nilai tersebut dibawah batas kritis penelitian atau titik signifikansi 0,05 (5\%). Dengan demikian hipotesa dalam penelitian ini adalah $\mathrm{HO}$ ditolak dan Ha yang berarti terdapat manfaat latihan body mekanik terhadap penurunnan nyeri pinggang pada ibu hamil trimester III PMB Bidan Utami tahun 2018.

\section{Daftar Pustaka}

[1] Mochtar, rustam. 2007. Sinopsis Obstetri. Jakarta : EGC

[2] Prawirohardjo,S.2008. Ilmu Kebidanan. Jakarta: Yayasan Bina Pustaka Sarwono Prawirohardjo.Profi Kesehatan.

[3] Bratanyatnya. 2008. Bisma Nyeri Pinggang Saat Hamil. Available at http://kamusbahasaindonesia. org. tanggal 14 Desember 2015.

[4] Varney,H. 2006. Buku ajar Asuhan Kebidanan Edisi 4.
Jakarta: EGC

[5] Snell, R. S. 2006. Anatomi Klinik. Edisi 6. Jakarta:EGC. 350-360.

[6] Pictran. 2011. Perubahan Sistem-Musculoskeletal-Pada ibu hamil dan nifas. Di akses dari id.scribd.com(http://id.shvoon g.com/medicine-and-health/ tanggal 13 Desember 2015.

[7] Potter, P. A., \& Perry, A. G. 2006. Buku Ajar Fundamental : konsep, proses, dan praktik. Jakarta : EGC

[8] Brown A and Mackler L. S, 2009. Diagnosis of Mechanical LBP in a laborer, journal of Orthopaedic \& Sport Physical Therapy, Volume 29 (10). American Physical Therapy Association: California.

[9] David Imrie. 2006. The Practical way to a pain-free and healthy back. Nort amerika suffer backpain.http//www.abebook. com/servlet/bookdetailsPL?bi :710327837

[10] Idyan, Zamna. 2007. Hubungan Lama Duduk Saat Perkuliahan dengan Low Back Pain http://www.innappni.or.id/ind ex.php?name

[11] Jenaka, Sateriya Sigit .2011. Kusmaryadi, Didi. Nyeri Pinggang Selama Kehamilan. Di akses dari www.kedokteran.info/tahapperkembangan- kehamilantrimesterketiga. 